Bull. Mater. Sci., Vol. 17, No. 6, November 1994, pp. 921-934. (C) Printed in India.

\title{
Electronic mechanism of sintering: Some case studies on real systems
}

\author{
G S UPADHYAYA \\ Department of Materials and Metallurgical Engineering, Indian Institute of Technology, \\ Kanpur 208 016, India
}

\begin{abstract}
The paper reviews the role of electronic configuration model of condensed state in explaining the sintering behaviour of various alloys. The systems are copper base alloys, ferrous alloys containing phosphorus, tungsten based heavy alloys, Al-refractory carbide composites, 6061 Al-alloy composites, high speed steel composites and tungsten carbide based cemented carbides. These studies cover the research activities of the Powder Metallurgy Laboratory at IIT, Kanpur.
\end{abstract}

Keywords. Sintering; powder metallurgy; electronic mechanism; sintered alloys; sintered particulate composites.

\section{Introduction}

Among the numerous attempts in interpreting the sintering mechanisms-reactions at the surface and particle boundaries, surface and volume diffusion and thermally activated dislocation processes are more prevalent. Considerable disagreement exists on the sintering mechanisms operative at different stages. Kuczynski (1949) propounded the diffusion mechanism, while Lenel (1966) used the concept of dislocation mechanism of deformation. In general, the concepts of diffusion theory, creep and recrystallization (Frenkel 1946; Pines 1954; Fedorchenko et al 1970) have been mainly used, each of which correctly reflects one or the other group of sintering phenomena. However the construction of these theories on an atomic level limits their possibilities and does not allow a single sintering theory, for which it is essential to consider these phenomenon on a subatomic electronic level (Samsonov 1967).

At present, a number of models of the condensed state of matter have been developed, including the model of configuration localization (Samsonov 1968; Samsonov et al 1971), which can be successfully applied in interpreting powder metallurgical processes. The essence of this model is that the valence electrons of isolated atoms are divided into localized and nonlocalized (collective) parts. The localized part forms configurations which are responsible for a minimum store of free energy. Such configurations are $s^{2}$ for $s$-elements, $d^{0}, d^{5}, d^{10}, f^{0}, f^{7}, f^{14}$ for transition metals and $s p^{3}$ and $s^{2} p^{6}$ for the sp-elements. The energetic stability of the $s$ - and $s p$-configuration decreases while that of the $d$ - and $f$-configurations increases with increase in the principal quantum number of the valence electrons. The electronic exchanges between stable and nonlocalized configurations is responsible for the attractive force between the atom cores, whereas electron-electron interaction between nonlocalized electrons is responsible for the repulsive force.

Assuming that for transition metal atoms in the free state with the number of 
$d$-electrons $n_{\mathrm{d}} \leq 5$, only two stable configurations $d^{\prime}$ and $d^{5}$ of localized electrons are formed, the statistical weight of atoms having stable configuration (SWASC), $d^{5}$ in the metallic crystal was reported (table 1): Similarly for metals with $5 \leq n_{\mathrm{d}} \leq 10$, the SWASC of $d^{5}$ and $d^{10}$ configurations were reported (table 1).

The correlation of self diffusivity data with electronic configuration has been done by Upadhyaya (1971c) elsewhere.

Numerous examples of the interpretation of diffusion parameter in heterogeneous systems have also been reported (Upadhyaya 1971a). They show that the electronic concept fully describes the process, irrespective of the fact to which class of electronic analog the partners of the system belong. Similarly it has been noticed that the activation energy for recrystallization of transition metals is a direct function of the degree of localization of the $d^{5}$ configurations. In case of refractory compounds based on early transition metals too a similar pattern is observed (Samsonov and Boschko 1970). A detailed review on electronic mechanism of powder metallurgical processing of high temperature material has been done by Samsonov and Upadhyaya (1972).

A common objective of sintering studies is the achievement of an understanding of the effect of sintering variables-temperature, time, applied pressure (if used), powder size, and composition (including additives and atmosphere control-so that

Table 1. Statistical weight of stable electronic configurations of transition metals.

\begin{tabular}{llrrr}
\hline & Electron & \multicolumn{3}{c}{ SWASC (\%) } \\
\cline { 3 - 5 } Metal & configuration & $d^{0}$ & $d^{5}$ & $d^{10}$ \\
\hline $\mathrm{Sc}$ & $3 d^{1} 4 s^{2}$ & 84 & 16 & 0 \\
$\mathrm{Ti}$ & $3 d^{2} 4 s^{2}$ & 57 & 43 & 0 \\
$\mathrm{~V}$ & $3 d^{3} 4 s^{2}$ & 37 & 63 & 0 \\
$\mathrm{Cr}$ & $3 d^{5} 4 s^{1}$ & 27 & 73 & 0 \\
$\mathrm{Fe}$ & $3 d^{6} 4 s^{2}$ & 0 & 54 & 46 \\
$\mathrm{Co}$ & $3 d^{7} 4 s^{2}$ & 0 & 28 & 72 \\
$\mathrm{Ni}$ & $3 d^{8} 4 s^{2}$ & 0 & 12 & 88 \\
$\mathrm{Cu}$ & $3 d^{10} 4 s^{1}$ & 0 & 8 & 92 \\
$\mathrm{Y}$ & $3 d^{1} 5 s^{2}$ & 73 & 27 & 0 \\
$\mathrm{Zr}$ & $4 d^{2} 5 s^{2}$ & 48 & 52 & 0 \\
$\mathrm{Nb}$ & $4 d^{4} 4 s^{1}$ & 24 & 76 & 0 \\
$\mathrm{Mo}$ & $4 d^{5} 5 s^{1}$ & 12 & 88 & 0 \\
$\mathrm{Ru}$ & $4 d^{7} 5 s^{1}$ & 0 & 80 & 20 \\
$\mathrm{Rh}$ & $4 d^{8} 5 s^{1}$ & 0 & 60 & 40 \\
$\mathrm{Pd}$ & $4 d^{10} 5 s^{10}$ & 0 & 18 & 82 \\
$\mathrm{Ag}$ & $4 d^{10} 5 s^{1}$ & 0 & 4 & 96 \\
$\mathrm{La}$ & $5 d^{1} 6 s^{2}$ & 70 & 30 & 0 \\
$\mathrm{Hf}$ & $5 d^{2} 6 s^{2}$ & 45 & 55 & 0 \\
$\mathrm{Ta}$ & $5 d^{3} 6 s^{2}$ & 19 & 81 & 0 \\
$\mathrm{~W}$ & $5 d^{4} 6 s^{2}$ & 0 & 96 & 4 \\
$\mathrm{Re}$ & $5 d^{5} 6 s^{2}$ & 0 & 94 & 6 \\
$\mathrm{Os}$ & $5 d^{6} 6 s^{2}$ & 0 & 84 & 16 \\
$\mathrm{Ir}$ & $5 d^{7} 6 s^{2}$ & 0 & 68 & 32 \\
$\mathrm{Pt}$ & $5 d^{1} 6 s^{1}$ & 0 & 40 & 60 \\
$\mathrm{Au}$ & $5 d^{10} 6 s^{1}$ & 0 & 10 & 90 \\
\hline & & & & \\
\hline
\end{tabular}


suitable control of variables can lead to products with the required microstructure (commonly small grain size) and high density.

One major difficulty in understanding the exact means of operation of an additive is that so many alternative mechanisms for these processes exist. Thus for example the additive can work as a second phase or as a solid solution. As a second phase (i) providing a continuous high diffusivity pathway e.g. liquid phase at the boundaries, and (ii) providing a continuous low diffusivity pathway at the boundaries for diffusion across the boundary which then acts to restrain grain boundary movement and as a solid solution (i) enhancing diffusion coefficients for the controlling species in the latice or parallel to the grain boundary by effecting the point defect concentrations in the boundary or lattice, (ii) slowing grain boundary movement by forming a segregated layer at the boundary which must then be pulled along by the boundary, (iii) altering the overall driving force for sintering by altering the ratio of grain boundary energy to free surface energy and (iv) slowing intrinsic grain boundary movement by reducing the diffusion coefficient for atom movement across the grain boundary, again by affecting the defect chemistry.

\section{Sintering and phase diagram}

Activated sintering allows for either a lower sintering temperature, a shorter sintering time, or improvement in properties from a chemical addition to the powder. One of the most dramatic examples of activated sintering occurs when tungsten or molybdenum is treated with certain transition metals (German and Munir 1982; Petzow et al 1982). Figure 1 shows an ideal phase diagram for activated sintering systems (German and Robin 1985). The factors are solubility, segregation and diffusion, as described here: (i) solubility: The additive must have a solubility in the base metal in order to exhibit a favourable effect on diffusion, (ii) segregation: during sintering, the additive must remain segregated at the interparticle interfaces to remain effective during the entire sintering cycle and (iii) diffusion: $D_{\mathrm{E}} \gg D_{\mathrm{B}}$, where $D_{\mathrm{E}}$ is the diffusivity of the base metal $\mathrm{B}$ in the additive layer, and $D_{\mathrm{B}}$ is the self diffusivity of the base metal $\mathrm{B}$.

In two-phase systems involving mixed powders, liquid formation is possible because of different melting ranges for the components. In such a system, the

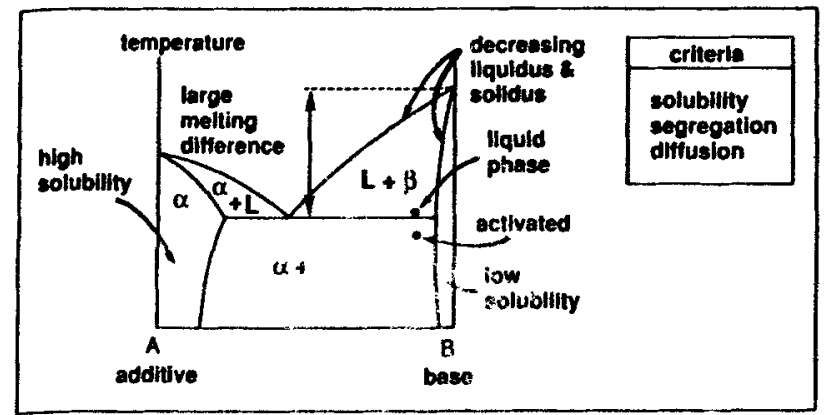

Figure 1. An idcalized binary phase diagram for an additive $A$ that acts to enhance the sintering of base metal B (Gurman and Rabin 1985). 
liquid may provide for rapid transport and therefore rapid sintering if certain criteria are met (Lenel 1980; German 1985; German and Robin 1985). These criteria are similar to those for activated sintering. The liquid must form a film surrounding the solid phase. Thus, wetting is the first requirement. Secondly, the liquid must have a solubility for the solid. Finally, the diffusive transport for the solid atoms dissolved in the liquid should be high enough to ensure rapid sintering. The formation of a liquid film provides the benefit of a surface tension force acting to aid densification and pore elimination. The correlation of such physical properties with the electronic structure has been done by Upadhyaya (1971b) elaborately. The relationships of the phase diagrams with electronic structure is also reported elsewhere (Samsonov and Upadhyaya 1969).

Upadhyaya and Bhattacharjee (1991) investigated the liquid phase sintering response of $\mathrm{Cu}$ base alloys containing various additives like $\mathrm{Ag}, \mathrm{Si}, \mathrm{Sn}$ and $\mathrm{Pb}$, such that the liquid phase was 5 mass $\%$. The sintering temperatures selected were 1.1 and 1.2 times greater, respectively than the corresponding isotherms in the binary phase diagrams. Results (figure 2) showed that the highest densification parameter among all the alloys considered was found in $\mathrm{Cu}-\mathrm{Si}$ alloy. It is worth noting that $\mathrm{Cu}-\mathrm{Si}$ forms a series of intermetallics whereas $\mathrm{Cu}-\mathrm{Ag}$ do not form any intermetallics. It is thus evident that in the former the sintering is more enhanced due to the better possibilities of segregation effect. As Si is a covalent bonding
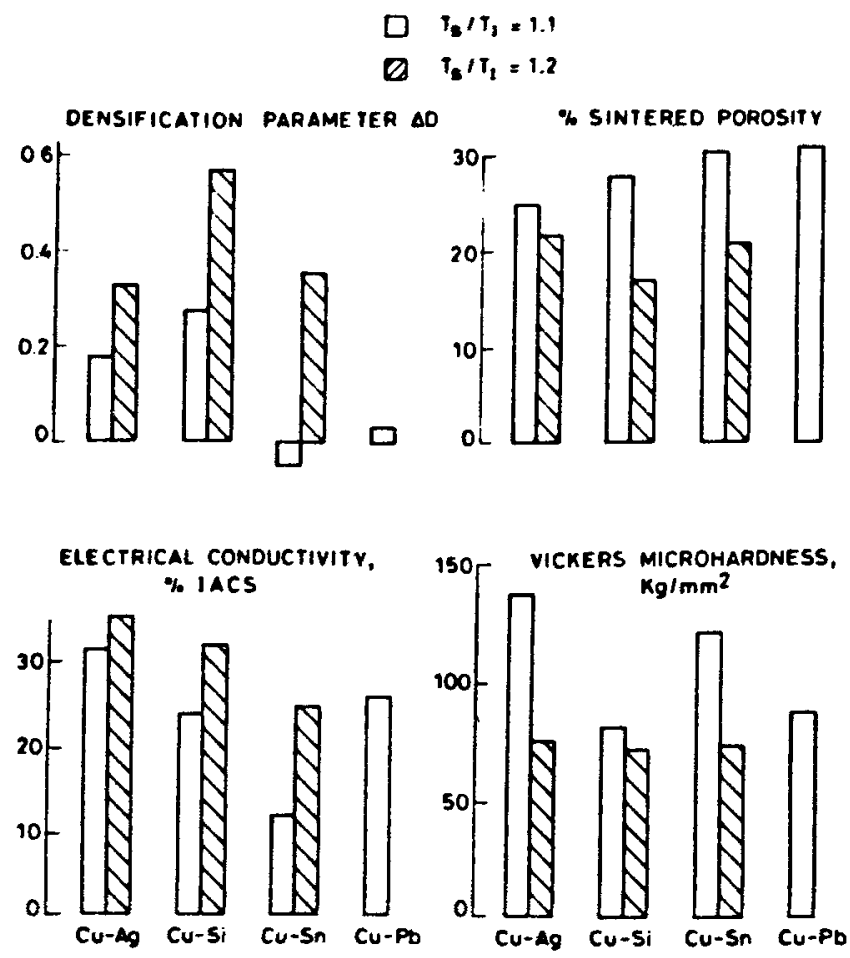

Figure 2. Sintered propertics of $\mathrm{Cu}$ base alloys liquid phase sintered at two-temperature ( $T_{s}$ and $T_{l}$ are the sintering and isotherm temperature respectively in degrees Kelvin) (Upadhyaya and Bhattacharjee 1991). 
additive, there is more directional bond, thus occupying more space, which in turn would demonstrate higher densification during sintering.

Another interesting example of the German model is in explaining the enhanced sintering of tungsten or molybdenum containing nickel as additive (figure 3 ).

\section{Specific case studies}

In the following sections the various findings on sintering studies on binary and multicomponent systems carried out at the Indian Institute of Technology, Kanpur have been briefly described and their interrelationships with the electronic structures have been highlighted.

\subsection{Copper based alloys}

The sintering results by Upadhyaya and Singhal (1979) on Cu-7Al premix containing transition metals $(0-3$ mass $\%)$ after $950^{\circ} \mathrm{C}$ sintering revealed that such additions imparted growth to the compacts in the descending order Co-Mo-Fe-Ni (figure 4). The very promising influence of nickel among all the transition metal additions in aluminium bronze has been justified by Mitani and Yokota (1975) who showed the suppressing of Kirkendall effect after nickel addition. thus lowering growth.
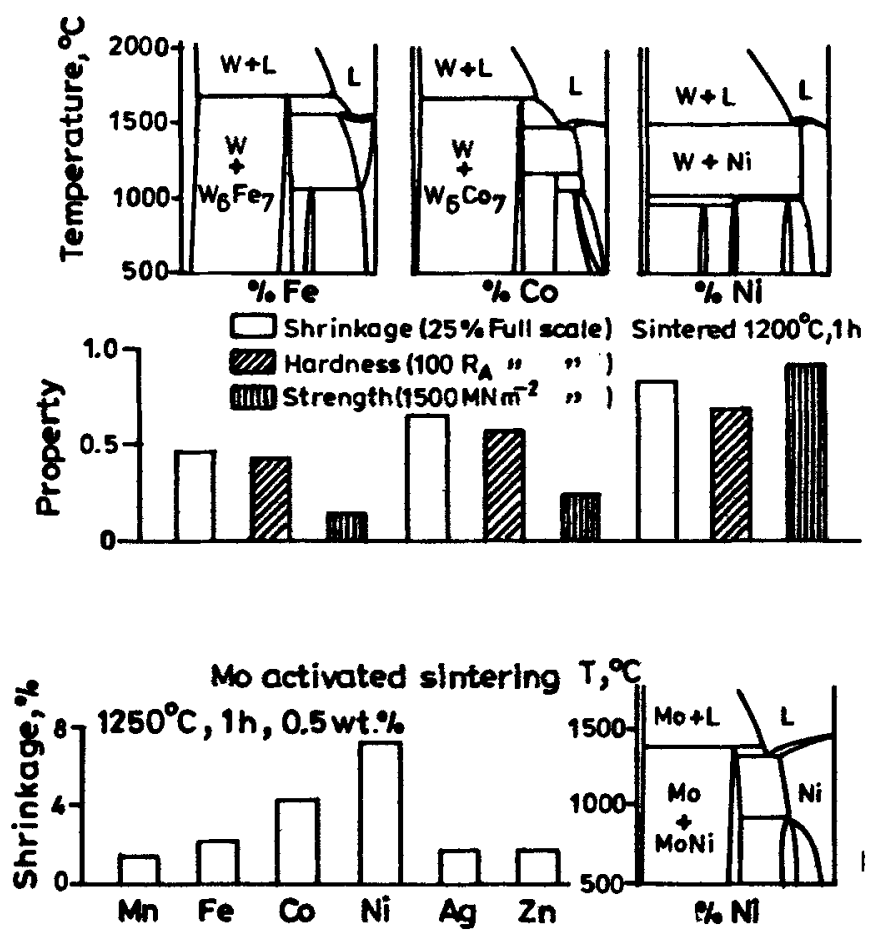

Figure 3. Comparison of phase diagrams and sintered properties for tungsten and molybdenum containing 0.5 mass\% transition metal additives (Rabin and German 1985). 


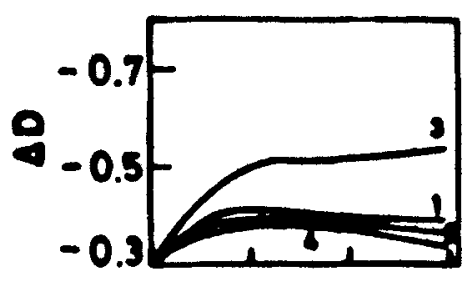
1. $\mathrm{Cu}-7 \mathrm{Al}-\mathrm{MO}$
2. CU-7Al-Fe
3. CU-7AI-CO
4. $\mathrm{CU}-\mathrm{TAI}-\mathrm{NI}$

\section{wt.\% Additive}

Figure 4. Sintering behaviour of $\mathrm{Cu}-7 \mathrm{Al}$ alloy containing transition metal additives (Upadhyaya and Singhal 1979).

For activated sintering to occur, one needs higher diffusivity, which in other words means higher contribution of nonlocalized valence electrons or lower SWASC values. This is the reason why molybdenum and cobalt having higher SWASC $d^{5}$ and $d^{16}$, respectively show relatively poor sinterability. However a question still remains unsolved as to why nickel with higher $d^{10}$ SWASC than iron and cobalt still shows opposite behaviour. This could be explained on the basis of Haworth and Hume-Rothery (1952) concept that with dissolution of nickel in copper or Cu-Al, the normal tendency to fill the $d$-shells is counteracted by the effect of the greater freedom of nickel atoms.

Diffusion data (Butrymowicz et al 1977) suggest that activation energy of interdiffusion of copper rich side of $\mathrm{Cu}-\mathrm{Ni}$ alloy decreases with increase in nickel concentration. Such a behaviour would naturally enhance densification due to increased diffusivity. A question remains unanswered as to why cobalt containing bronze also shows a similar pattern with increase in cobalt content, although the activation energy pattern is other way round. This may be correlated with the possibility of increase in SWASC $d^{10}$ in cobalt with increase in temperature, a feature more pronounced in cobalt, which has lower SWASC $d^{10}$ than nickel at ordinary temperature.

A detailed investigation on sintering of prealloyed $\mathrm{Cu}-35.6 \mathrm{Zn}$ brass powder with transition metal additives like molybdenum, iron, cobalt and nickel (up to 3 mass\%) was carried out by Srivastava and Upadhyaya (1985). Sintering temperatures were 700,800 and $850^{\circ} \mathrm{C}$, the atmosphere being dry hydrogen. The densification behaviours with iron or cobalt additions were similar, being superior to those with molybdenum or nickel addition (figure 5). This suggests that the metals with highest $d^{5}$ or $d^{10}$ configurations exhibit indifferent behaviour, while those with intermediate range of $d^{5}$ configurations i.e. iron and cobalt, have better probability of interaction and thus impart densification.

\section{$3.2 \mathrm{Fe}-\mathrm{P}-\mathrm{X}(\mathrm{X}=\mathrm{Mo}, \mathrm{Ni}, \mathrm{Cu})$ alloys}

Hamiuddin and Upadhyaya $(1979,1980 \mathrm{a}, \mathrm{b})$ did extensive investigation on the liquid phase sintering of Fe-P- $X$ systems, and found that Mo addition imparted maximum densification among all (figure 6). Next to this came nickel and finally copper, which have energetic stability in the descending order. It is noteworthy that copper 

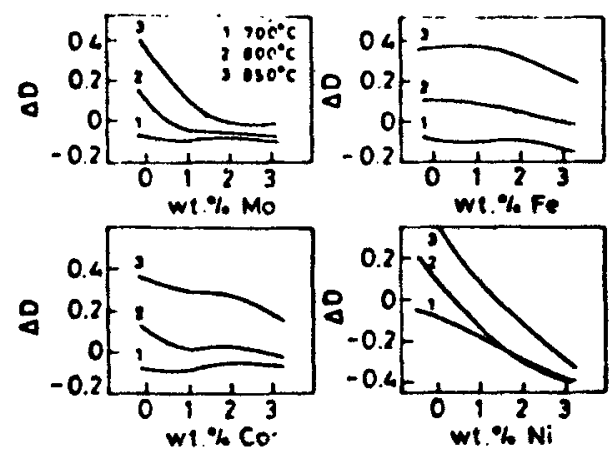

Figure 5. Sintering behaviour of brass containing transition metal additives (Srivastava and Upadhyaya 1985).
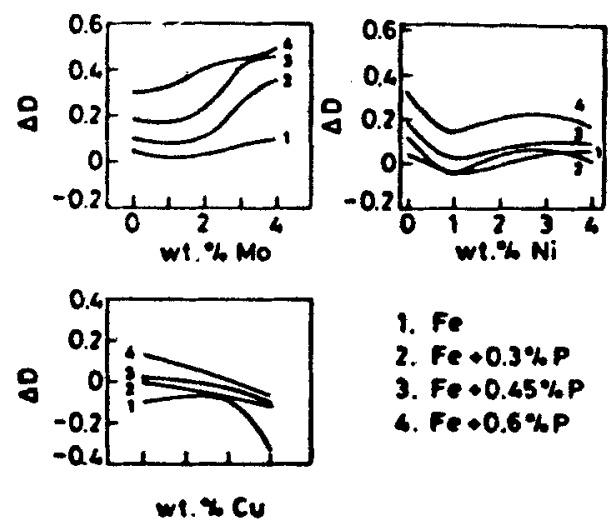

1. Fe

2. Fe $+0.3 \% P$

3. Fe $0.45 \% P$

4. Fe $0.6 \% p$

Figure 6. Sintering behaviour of Fe-P premixes containing transition metal additives (Hamiuddin and Upadhyaya 1979, 1980a, b).

having filled $d^{10}$ electrons tries to maintain its own environment during alloying, thus imparting growth. As far as nickel is concerned, which has two $3 d$-electron vacancies, one needs a greater proportion of its addition in iron for densification. In other words, in lower nickel concentration the densification behaviour of iron is an extension of what is observed in $\mathrm{Fe}-\mathrm{Cu}$ alloys i.e. growth.

\subsection{Tungsten based heavy alloys}

Srikanth and Upadhyaya (1985a, b) and Upadhyaya and Srikanth (1985a, b) studied the sintering of $90 \mathrm{~W}-10(X, \mathrm{Ni})$ heavy alloy system with varying proportions of $X(\mathrm{Cu}, \mathrm{Fe}, \mathrm{Co}$ or $\mathrm{Cr})$ from $0-100 \%$. The results established that after sintering at $1500^{\circ} \mathrm{C}$ for $1 \mathrm{~h}$ densification increased in the sequence $\mathrm{Cr}-\mathrm{Cu}-\mathrm{Fe}-\mathrm{Co}-\mathrm{Ni}$ (figure 7). A cursory look on the solubility relationship of tungsten in the binder metals reveals that the maximum solubility falls in the sequence $\mathrm{Ni}(40 \%)-\mathrm{Co}(35 \%)-\mathrm{Fe}$ 


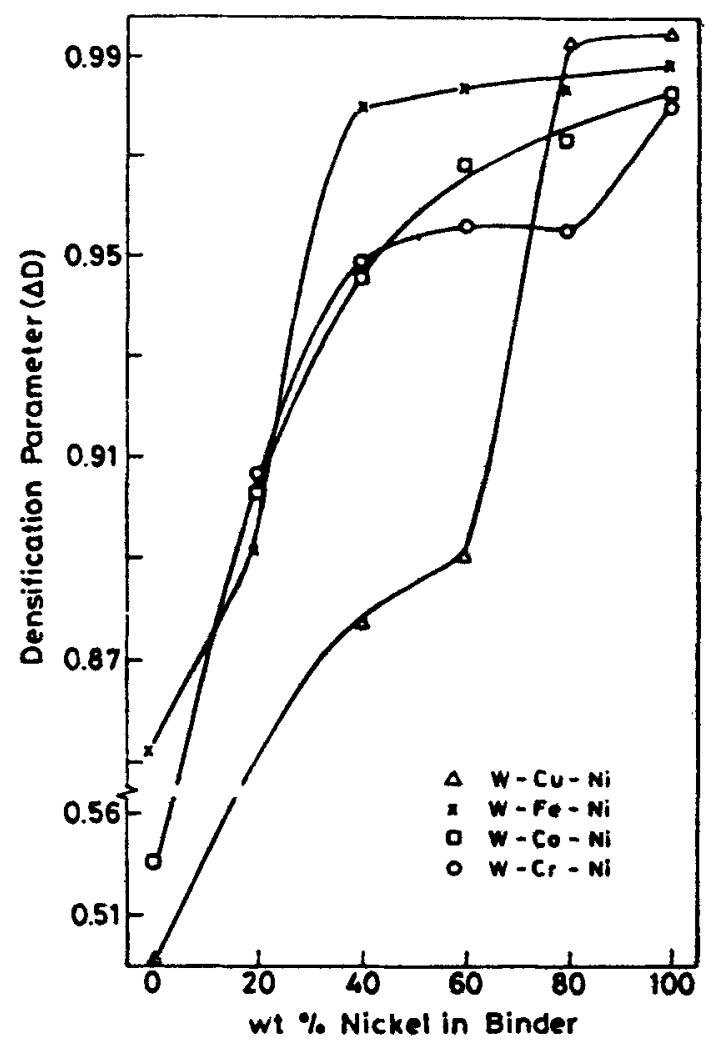

Figure 7. Sintering behaviour of various tungsten based heavy alloys (Srikanth and Upadhyaya 1985a, b).

(33\%) $-\mathrm{Cu}(0 \%)$. The W-Cr binary phase diagram is entirely different from the others in the sense that it forms isomorphous solid solution at elevated temperatures with some miscibility gap. This is the reason why all the results on $\mathrm{W}-\mathrm{Cr}-\mathrm{Ni}$ heavy alloys presented by the author do not follow a clear cut correlation. As the difference in $d^{5}$ statistical weight between tungsten and chromium is not very large; they form isomorphous solid solutions. On the other hand a very large difference in statistical weight as in the case of W-Cu (88\%) results in practically no interaction, whereas the situation for other transition metal binaries are intermediate ones.

\subsection{Al-refractory carbide composites}

Aluminium refractory carbides are a unique combination in which both aluminium and carbon belong to sp electronic configuration. Upadhyaya and Misra (1978) studied such composites with carbides like $\mathrm{TiC}, \mathrm{ZrC}, \mathrm{Cr}_{3} \mathrm{C}_{2}, \mathrm{NbC}, \mathrm{Mo}_{2} \mathrm{C}$ and $\mathrm{WC}$. $\mathrm{TiC}$ addition gave highest densification, while $\mathrm{Cr}_{3} \mathrm{C}_{2}$ the least (figure 8). As it is well known, TiC, because of its highest degree of SWASC $s p^{3}$, has the highest hardness among all the carbides, which would promote residual stresses at the metal matrix interface and thus activate the sintering process. The poor response 


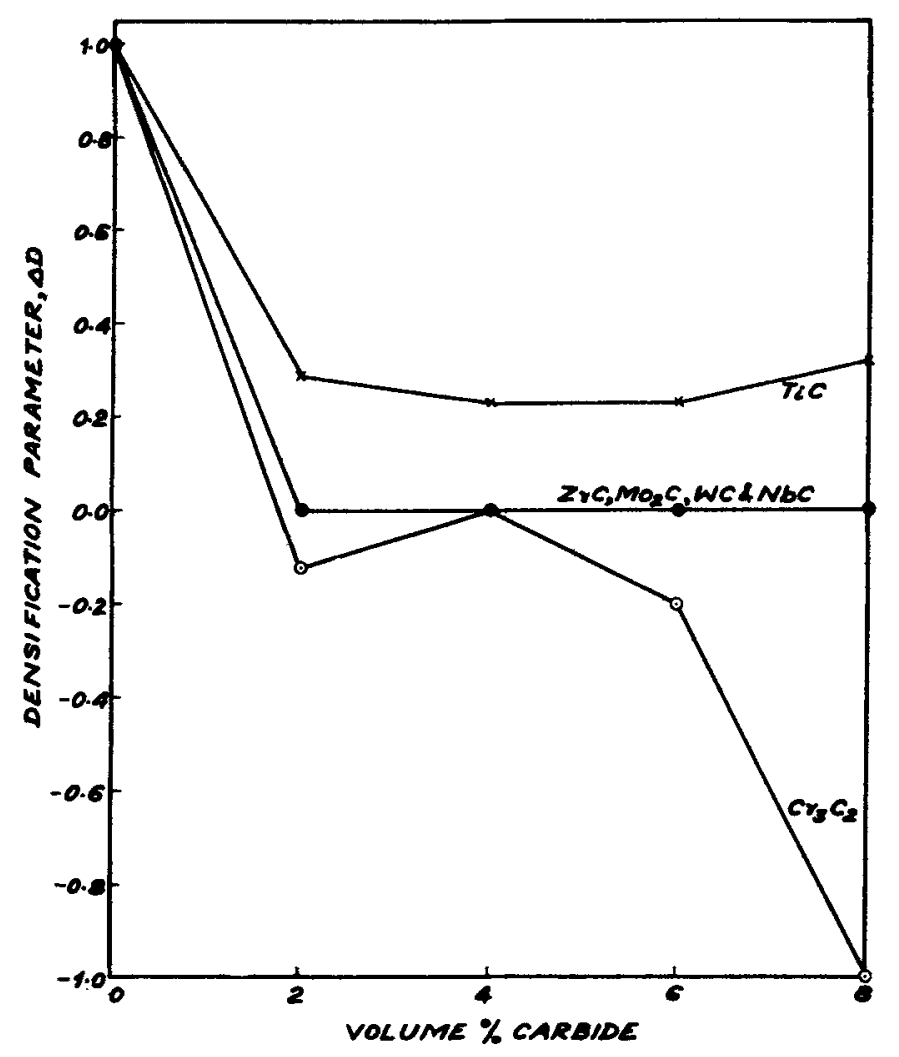

Figure 8. Densification behaviour of Al-carbide sintered composites (Upadhyaya and Misra 1978).

by $\mathrm{Cr}_{3} \mathrm{C}_{2}$ having lower SWASC $s p^{3}$ is also due to its complex crystal structure (rhombohedral), which incorporates a higher degree of anisotropy in the system. While considering the stable configuration formation, the question arises which of the two $s p$ type element $\mathrm{C}$ or $\mathrm{Al}$ will have the higher energetic stability for $s p^{3}$ configuration. The answer is carbon, as it has lower principal quantum number in comparison to aluminium. A more conclusive picture can be drawn, when it is assumed that nonlocalized electrons strongly form hybrid states with both $d^{n}$ and $s^{x} p^{y}$ states.

\subsection{The 6061 Al-alloy based composites}

The 6061 aluminium alloys contain silicon and magnesium to render them heat treatable. If one looks at the relevant binary phase diagrams, it is apparent that the difference in the melting point of base metal aluminium and the entectic isotherm of $\mathrm{Al}-\mathrm{Mg}\left(211^{\circ} \mathrm{C}\right)$ is greater than that for $\mathrm{Al}-\mathrm{Si}\left(86^{\circ} \mathrm{C}\right)$. Further, the solubility of magnesium in aluminium is 12 mass $\%$, whereas the solubility of the other constituent namely silicon is practically nil. This clearly indicates that the presence of magnesium in 6061 alloy has a pivotal role during sintering. From the 
electronic strength point of view all the three elements i.e. $\mathrm{Mg}, \mathrm{Al}$ and Si belong to the same period in the Periodic Table with similar outmost electronic configuration. Magnesium being metallic in nature is more compatible with aluminium as compared to silicon, which has covalent $(s p)$ bond. The higher solubility of magnesium in aluminium as compared to silicon in aluminium is a direct manifestation of this fact.

Jha et al (1988, 1990) extensively studied sintering of 6061 Al-alloy based composites containing soft (graphite and talc) and hard (alumina and TiC) particles. Apart from the physical modelling of densification, the role of chemical bonds within the dispersoid and at matrix/dispersoid interfaces is also important. Both graphite and talc have weak Vander Waal type forces between the layered structures, whereas, alumina and $\mathrm{TiC}$ are covalently or covalent/ionic bonded. The sintered porosity variation of 6061 base composite (figure 9) amply illustrates the above fact such that graphite/talc addition increases porosity level, whereas, $\mathrm{TiC}$ and alumina addition exhibit reverse trend.

\subsection{High speed steel composites}

High speed steels (HSS) are a range of highly alloyed steels which offer high hot hardness, wear resistance and toughness. These properties are best achieved by an alloy consisting of uniform dispersion of fine, hard, stable particles such as carbides in a tough matrix. Supersolidus liquid phase sintering of high speed steels is a standard economical practice, which avoids carbide segregation and grain growth. Kar and Upadhyaya (1990, 1991) and Upadhyaya and Kar (1992, 1993) extensively studied the role of $\mathrm{TiC}$ and $\mathrm{TiN}$ additives up to $8 \mathrm{Vol}$ \% on sintering behaviour of $\mathrm{T} 15$ (Cr 4.23, Co 4.99, Mo 0.55, W 12.50, V 4.75, C 1.59\%) and $\mathrm{T} 42(\mathrm{Cr}$ 3.96, Co 10.60, Mo 4.01, W 9.70, V 2.39 and C 1.38\%) grades of high speed steels.

From the literature survey it emerges that all the refractory compound enriched HSS compositions can be classified into three groups. The first group of compounds, which dissolve completely in the matrix at the sintering temperature, do not serve

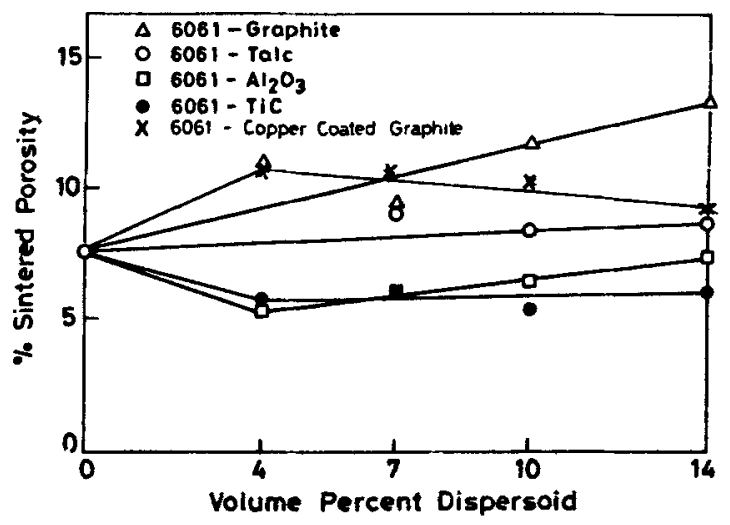

Figure 9. Variation of porosity of argon sintered 6061 alloy based composites as a function of dispersoid content (Jha and Upadhyaya 1988). 
in developing any worthwhile composite. Examples of such compounds are silicon carbide and chromium carbide in steels. The second group of compounds are refractory carbides such as $\mathrm{WC}, \mathrm{Mo}_{2} \mathrm{C}$ and $\mathrm{VC}$ etc. which are inherent in the microstructure of the steels. Their evolution can be brought about by a change in the chemistry and heat treatment of the steel. The presence of such compounds does not change the sintering conditions as wettability and bonding in the matrix do not pose any problem. The third group of refractory compounds are those which remain stable in the matrix at still high temperatures. TiC and TiN fall in this group of the refractory compounds. The relative advantage of their addition depends on the wetting characteristics and so the bonding between the hard particles and matrix. TiC has better wetting behaviour (contact angle $<90^{\circ}$ ) as compared to TiN (contact angle $>90^{\circ}$ ) with iron. Better densification behaviour in case of $\mathrm{TiC}$ containing composites based on either T15 or T42 HSS in comparison to those containing $\mathrm{TiN}$ (figure 10 ) is related to the higher wettability of $\mathrm{TiC}$ as compared to TiN. For either of the selected refractory compound, it is obvious that composites based on T42 HSS have better densification behaviour in comparison to the corresponding T15 HSS based composites. This difference in the densification behaviour is attributed to molybdenum and relatively higher cobalt content in T42 HSS than that in T15 HSS.

The distinctive densification response in either $\mathrm{TiC}$ or $\mathrm{TiN}$ containing composites
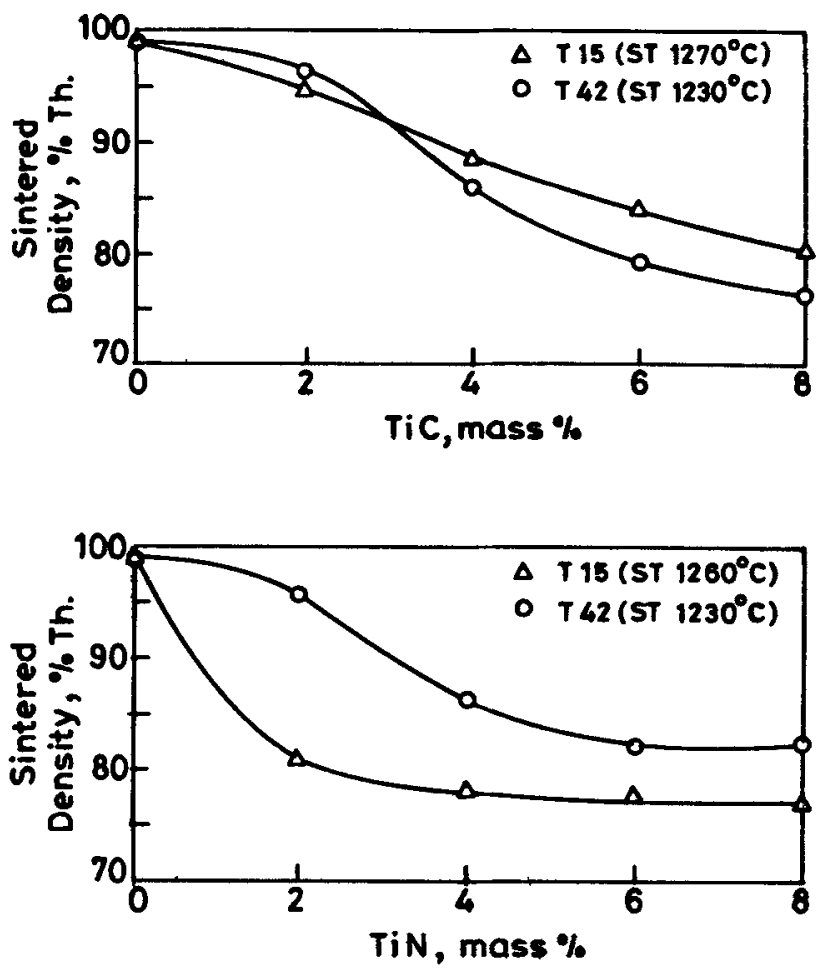

Figure 10. Effect of TiC and TiN additions on the densification of T15 and T42 grade high speed steels after supersolidus liquid phase sintering (Upadhyaya and Kar 1992, 1993). 
can be adequately correlated on the basis of the differences in bondings, which these compounds possess. Titanium in refractory compounds e.g. TiC/TiN, pertains to early transition metal containing unfilled $d$ shell, while both carbon and nitrogen correspond to $s p$ electronic configuration for their valency electrons. Samsonov (1969) discussed in detail the energetic stability of both types of elements and concluded that during formation of such refractory compounds the transition metals act as donors of electrons, so as to stabilize the $s p^{3}$ configuration of non metal atoms to different extents. Carbon whose isolated atoms possess $s^{2} p^{2}$ electronic configuration tend to acquire stable $s p^{3}$ configuration due to $s-p$ transition during TiC formation. However, in case of nitrogen, whose isolated atoms have $s^{2} p^{3}$ configuration, owing to $s-p$ transitions by the scheme $s p^{4} s p^{3}+p$, they fully tend to acquire $s p^{3}$ configurations with one weakly bonded electron of $p$ configuration. It is this extra unbonded electron which is responsible for relatively lower hardness, lower melting point and higher plasticity in TiN as compared to strongly covalent bonded TiC. The poor wettability of TiN with HSS meit is a direct manifestation of the above fact. Moreover, the enhanced matrix grain coarsening in case of TiN containing composites in a way is also related with the above findings, since in order to acquire full density a relatively higher sintering temperature was necessary.

\subsection{WC based cemented carbides}

Upadhyaya and Basu (1985) reported sintering results on WC-10 Co hard metals, where the cobalt binder was partially or fully substituted by other transition metals like iron and nickel. For an efficient liquid phase sintering, wettability of melt is an essential criterion. WC has excellent wettability with iron-group transition metals, as compared to IV and V group transition metal carbides. This has been explained elsewhere (Upadhyaya 1984) on the basis of chemical bonding in the respective refractory carbides. The solubility of carbide phase in the binder melt can also be explained on the basis of above reasonings. Among all the binders studied by authors. WC-Fe and WC-Co form pseudobinary systems whereas WC-Ni does not. The almost filled $d$ configuration of nickel, brings forth the obvious conclusion as to why WC-Ni hard metal is not an ideal one. Solubility data confirm that cobalt $\left(\mathrm{MP} 1495^{\circ} \mathrm{C}\right.$ ) dissolves $10-22 \%$ of $\mathrm{WC}$ at the eutectic temperature of $1320^{\circ} \mathrm{C}$, whereas iron (MP $1535^{\circ} \mathrm{C}$ ) dissolves a lower quantity $(7.5 \%)$ at the corresponding eutectic temperature $\left(1143^{\circ} \mathrm{C}\right)$. The results show that iron may be an efficient binder candidate provided WC solubility range in it could be increased. Although the solubility of WC in nickel is not small, the exploitation of the system could not be made as they do not fall in an equilibrium pseudobinary system.

The continued increase in the consumption of WC based cemented carbides and the threat from the depleting resources of tungsten and cobalt have attracted a lot of attention so as to develop alternate composition compatible with WC-Co based ones. The most reasonable approach seems to dilute WC by other refractory carbides and partial replacement of the cobalt binder by nickel, iron or their alloys. Bhaumik et al (1992a, b; 1994) extensively studied the sintering behaviour of WC-10 Co corresponding to 17 Vol. \% binder phase. All the subsequent compositions developed were tailored so that the volume fraction of hard and binder phases remained constant as that of the initial WC-10Co cemented carbide. The hard phase WC was replaced by $\mathrm{TiC}, \mathrm{Ti}(\mathrm{CN})$ or $\mathrm{TiN}$ about one third by volume. The partial 


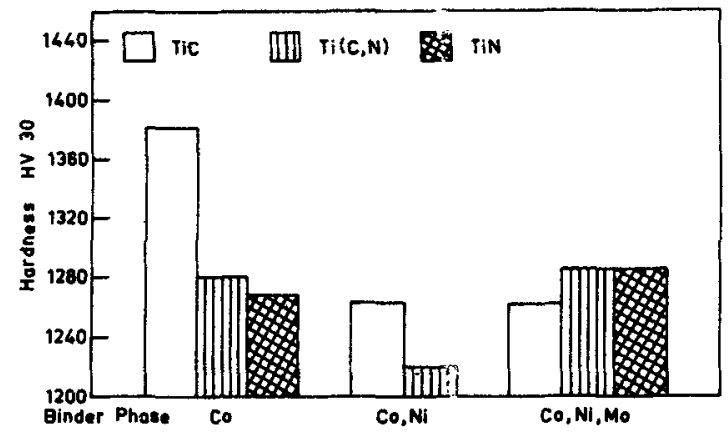

Figure 11. Hardness variation of WC-10 Co based cemented carbides as a function of binder phase substitution (Bhaumik et al 1992a, b, 1994).

substitution of cobalt $(50 \%)$ by nicke in binder necessitated the introduction of $\mathrm{Mo}_{2} \mathrm{C}$ for better wettability. In general, t was noticed that the properties of $\mathrm{Ti}(\mathrm{C}, \mathrm{N})$ containing cemented carbides were intermediate to those containing $\mathrm{TiC}$ or $\mathrm{TiN}$ irrespective of the change in the binder chemistry. The properties of the former group i.e. those containing $\mathrm{Ti}(\mathrm{C}, \mathrm{N})$ were however, much closer in magnitude to those containing TiN (figure 11). It is interesting to note that both $\mathrm{TiN}$ or $\mathrm{Ti}(\mathrm{C}, \mathrm{N}$ ) additions to WC-10 Co cemented carbide gave rise to processing difficulties such that the full density was not achieved during normal pressureless liquid phase sintering. This necessitated the application of another step hot isostatic compaction after the liquid phase sintering. The role of electronic structure of component atoms in the refractory compounds has alreariy been highlighted in $\$ 3.5$.

\section{Conclusions}

It follows from the above considerations that consolidation process through sintering can be interpreted on the electronic structure, making it possible to propose a unified theory. To this end, it is essential to concentrate attention on the physico-chemical process of materials during sintering and also as the quantitative development of the model of electronic structure so as to establish a direct relationship between the electronic structure, technological parameters and the end materials properties.

\section{Acknowledgements}

The author gratefully acknowledges IIT, Kanpur and the Ministry of Human Resource Development, Government of India for providing funds and infrastructural facilities for carrying out this work. The share of the work goes to his numerous past and present research students.

\section{References}

Bhaumik S K, Upadhyaya G S and Vaidya M L 1992a J. Mater. Sci. 271947

Bhaumik S K, Upadhyaya G S and Vaidya M L 1992b Int. J. Refract. Metals \& Hard Mater. 119 Bhaumik S K, Upadhyaya G S and Vaidya M L 1994 J. Mater. Sci. 2954 
Butrymowicz D B, Manning J R and Read M E 1977 Diffusion rate data mass trunsport phenomena for copper systems (Washington: National Bureau of Standards)

Fedorchenko I M et al (eds) 1970 Modern problems in powder metallurgy (in Russian) (Kiev: Naukova Durnka)

Frenkel Ya I 1946 Zhu Exp. Teor. Fiz. 1629

German R M 1985 Liquid phase sintering (New York: Plenum Press)

German R M and Munir Z A 1982 Rev. Powder Metall. Phys. Ceram. 29

German R M and Robin B H 1985 Powder Metall. 287

Hamiuddin M and Upadhyaya G S 1979 Trans. Powder Metall. Assoc. India 657

Hamiuddin M and Upadhyaya G S 1980a Powder Metall. 23136

Hamiuddin M and Upadhyaya G S 1980b Int. J. Powder Metall. Powder Technol. 1657

Haworth H B and Hume Rothery W 1952 Philos, Mag. 43613

Jha A K, Prasad S V and Upadhyaya G S 1988 Powder Metall. Int. 2018

Jha A K, Prasad S V and Upadhyaya G S 1990 Z. Metallkunde 81457

Kar P K and Upadhyaya G S 1990 in Proc. of lst int. high speed steel conf. (eds) H Hackl and B Hribernick (Leoben: Montan Universitat) pp. 477-485

Kar P K and Upadhyaya G S 1991 Steel Res. 62352

Kuczynskí G C 1949 Trans. AIME 85169

Lenel F V 1966 in Modern developments in powder metallurgy (ed.) H H Hausner (New York: Plenum Press) Vol. 1

Lenel F V 1980 Powder metallurgy principles and applications (Princeton: Metal Powder Industries Federation) pp. 211-267

Mitani $\mathrm{H}$ and Yokota M 1975 Trans. JIM 116502

Petzow G, Kaysser W A and Amtenbrink M 1982 in Sintering theory and practice (eds) D Kolar, S Pejovnik and M M Ristic (Amsterdam: Elsevier Scientific Publishers) pp. 27-36

Pines Ya I 1954 Usp. Fiz. Nauk 52501

Rabin B H and German R M 1985 in Physical metallurgy and technology of molybdenum and its alloys (eds) K H Miska, M Semchyshen and E P Whelan (Ann Arbor: AMAX Materials Research Centre) p. 101

Samsonov G V 1967 Planseeber. Pulvermetall. 152

Samsonov G V 1968 Fiz. Khim. Mater. 4502

Samsonov G V 1969 in High temperature materials, Proc. 6th Plansee seminar (ed.) F Benesovsky (Reutte, Austria: Metallwerk Plansee)

Samsonov G V and Upadhyaya G S 1969 J. Less Common Metals 17161

Samsonov G V and Boschko S A 1970 Planseeber. Pulvermetall. 18166

Samsonov G V and Upadhyaya G S 1972 Planseeber. Pulvermetall. 20269

Samsonov G V, Prydko I F and Prydko L F 1971 Configurational model of materials (New York: Consultant Bureau)

Srikanth V and Upadhyaya G S 1985a Trans. PMAI 1216

Srikanth V and Upadhyaya G S 1985b J. Less Common Metals 120213

Srivastava V C and Upadhyaya G S 1985 Truns. Powder Metall. Assoc. India 1222

Upadhyaya G S 1971a Scr. Metall. 51125

Upadhyaya G S 1971b Trans. Indian Inst. Metals 2448

Upadhyaya G S 1971c Metall. Trans. 3912

Upadhyaya G S (ed.) 1984 in Sintered metal ceramic composites (Amsterdam: Elsevier) p. 41

Upadhyaya G S and Misra P S 1978 Sci. Sinter. 10157

Upadhyaya G S and Singhal S K 1979 in Proc. of Vth powder metallurgy conf., Poznan (Warsaw: Polish Academy of Science) Vol. III, p. 15

Upadhyaya G S and Basu D 1985 in Proc. of llth int. Plansee seminar (eds) H Bildstein and H M Ortner (Reutte, Austria: Metallwerk Plansee) Vol. 2, p. 559

Upadhyaya G S and Srikanth V 1985a in Proc. of 11th int. Plansee seminar (eds) H Bildstein and H M Ortner (Reutte, Austria: Metallwerk Plansee) Vol. 2, p. 203

Upadhyaya G S and Srikanth V $1985 \mathrm{~b}$ in Modern development in powder metallurgy (eds) E N Aqua and $\mathrm{C} I$ Whitman (Princeton: Metal Powder Industries Federation) Vol. 15-17, p. 5

Upadhyaya G S and Bhattacharjee A 1991 Int. J. Powder Metall. 2775

Upadhyaya G S and Kar P K, 1992 in Sintering 1991 (eds) A C D Chaklader and J A Lund (Zurich: Trans. Tech. Publ.) p. 479

Upadhyaya G S and Kar P K 1993 in Proc. 3rd int. Plansee seminar (eds) H Bildstein and R Eck (Reutte, Austria: Metallwerk Plansee) Vol. 2, p. 328 